Epidemiology and Psychiatric

Sciences

\section{cambridge.org/eps}

\section{Editorial}

Cite this article: Griffiths SL, Wood SJ, Birchwood M (2019). Vulnerability to psychosocial disability in psychosis. Epidemiology and Psychiatric Sciences $\mathbf{2 8}$ 140-145. https://doi.org/10.1017/ S2045796018000495

Received: 17 July 2018

Accepted: 7 August 2018

First published online: 12 September 2018

\section{Key words:}

Cognition; early intervention and prevention; outcome; psychosocial functioning

Author for correspondence:

Sian Lowri Griffiths,

E-mail: s.l.griffiths@bham.ac.uk

\title{
Vulnerability to psychosocial disability in psychosis
}

\section{S. L. Griffiths ${ }^{1}$, S. J. Wood ${ }^{1,2,3}$ and M. Birchwood ${ }^{4}$}

${ }^{1}$ School of Psychology, University of Birmingham, Birmingham, UK; ${ }^{2}$ Orygen, the National Centre of Excellence in Youth Mental Health, Melbourne, Australia; ${ }^{3}$ Centre for Youth Mental Health, University of Melbourne and ${ }^{4}$ Warwick Medical School, University of Warwick, Coventry, UK

\begin{abstract}
Psychosocial disability affects a number of individuals with psychosis and often begins years before the formal onset of disorder. This suggests that for many, their psychosocial disability is enduring, and targeted interventions are therefore needed earlier in their developmental trajectories to ensure that psychosocial disability does not become entrenched. Poor psychosocial functioning also affects individuals with a range of different emerging mental health problems, putting these young people at risk of long-term social marginalisation and economic disadvantage; all of which are known risk factors for the development of psychosis. Identification of the markers of poor psychosocial functioning will help to inform effective treatments. This editorial will discern the early trajectories and markers of poor psychosocial outcome in psychosis, and highlight which individuals are most at risk of having a poor outcome. This editorial will also discuss whether early interventions are currently being targeted appropriately and will propose how intervention and preventative strategies can be implemented, to restore psychosocial trajectories in a way that enables young people to maximise their life chances.
\end{abstract}

\section{Introduction}

Psychosocial disability is a term which describes social and economic challenges or consequences which can be associated with one's mental health condition, affecting a person's ability to participate fully in society, such as being involved in work or education, engaging in interpersonal relations and social activities (United Nation Convention on the Rights of Persons with Disabilities, 2016). Psychosis is the most common cause of psychosocial disability world-wide (Hafner and an der Heiden, 1999). In the UK, an estimated cost of $£ 3.4$ billion per annum is attributed to unemployment, absence from work and premature death in individuals with psychosis (Mangalore and Knapp, 2007). Psychosocial disability, or poor functioning, emerges long before the formal onset of psychosis, but peaks at illness onset and plateaus thereafter, suggesting that disability is a longstanding trait rather than direct sequela of the symptoms used to classify the disorder - hallucinations, delusions and thought disorder (Agerbo et al., 2004). In contrast, these symptoms peak at the onset of illness, but typically resolve - often with the initiation of anti-psychotic medication. However, it is now widely acknowledged that anti-psychotic medication has little positive impact on psychosocial disability (McGorry et al., 2008), highlighting that symptoms and functioning are not causally related and indicating the need for alternative therapeutic approaches.

The first episode of psychosis (FEP) often occurs in adolescence; this is a critical time for the young person's identity formation, development of social networks and the beginnings of a vocational career; thus, disruption to an individual's social relationships and academic or work performance at this time can have a profound negative impact on their social and interpersonal trajectories (Hafner and an der Heiden, 1999; McGorry et al., 2008). Hafner and an der Heiden (1999) suggested that the number of social developmental milestones achieved prior to the onset of illness would strongly influence and perhaps place a limit on the longterm psychosocial outcomes. Indeed, longitudinal studies have shown that psychosocial disability at illness onset is strongly predictive of disability many years later (Addington et al., 2005; Alvarez-Jimenez et al., 2012; Tandberg et al., 2012), and those with an earlier onset of illness are likely to have a poorer psychosocial outcome (Hafner and an der Heiden, 1999). The logic of this is that interventions which target psychosocial functioning in the initial stages of psychosis hold out the prospect of preventing long-term psychosocial disability. These facts about the early trajectories of disability informed the concept of the adolescent and early phase of psychosis as a 'critical period' influencing the longer-term outcome (Birchwood and Macmillan, 1993; Birchwood et al., 1998). 
Early trajectories of psychosocial functioning: are early interventions being targeted appropriately?

Early Intervention Services (EIS), which provide specialist assertive outreach-style care during the 'critical period' (Birchwood et al., 1998), are considered the 'gold standard' treatment for young people with early psychosis (National Institute of Clinical Excellence NICE guidelines, 2014). Whilst EIS has shown to have substantive benefits in a number of domains, including vocational and educational outcomes (Fowler et al., 2009; Correll et al., 2018), a recent large UK EIS cohort study $(n=878)$ showed a large proportion (66\%) of young people continue to have a high level of psychosocial disability, despite receiving care under EIS for a period of 12 months following referral for a FEP (Hodgekins et al., 2015a). Furthermore, the majority (53.6\%) of individuals were 'not in education, employment and training' (known as NEET in the UK), and were spending as little as $25 \mathrm{~h}$ a week in meaningful structured activities such as socialising, studying, working and engaging in leisure activities; this is compared with $60+\mathrm{h}$ in healthy peers of a similar age (Hodgekins et al., 2015b). Thus, there appears to be a group of individuals whose disability is 'unresponsive' to standard high quality EIS care embodying NICE approved interventions, strongly suggesting that further targeted interventions are urgently needed to restore social trajectories in a way that enables young people to maximise their life chances.

Poor psychosocial functioning also affects individuals who fulfil criteria for ultra-high-risk (UHR) of developing psychosis (Cornblatt et al., 2007; Lin et al., 2011; Cotter et al., 2014; Heinze et al., 2018), with a study showing as many as $50 \%$ of UHR individuals meet criteria for social disability (Hodgekins et al., 2015b). This underlines the notion that disability in FEP begins before the formal onset. Indeed, higher psychosocial disability has also been associated with increased risk of transition to psychosis in the UHR group (Fusar-Poli et al., 2010; Velthorst et al., 2010; Cornblatt et al., 2012), suggesting that early disability is likely to serve as a risk factor for the development of psychosis (Cornblatt et al., 2012). However, studies have emerged which show that many UHR young people remain functionally impaired, irrespective of whether they transition to psychosis (Lin et al., 2011; Cotter et al., 2014). Given the high prevalence of disability in the UHR group, irrespective of their transition to psychosis, this suggests that disability arises for reason other than transition to psychosis.

A recent large naturalistic cohort study of young people with a range of emerging mental health disorders (not exclusively psychosis), revealed that as many as $69 \%$ had persistent severe psychosocial disability, despite receiving some form of early intervention care (Iorfino et al., 2018). We argue therefore that psychosocial disability is a transdiagnostic issue among young people affected by mental health issues: consistent with findings from FEP samples, a significant amount of heterogeneity in functional outcome has also been observed for individuals with other emerging mental health problems in adolescence; however, for those who presented with severe functional impairments upon entry to clinical services, their impairments were persistent over the course of treatment (Hodgekins et al., 2015a; Heinze et al., 2018; Iorfino et al., 2018), again showing that for many, these deficits are potentially enduring.

Whilst it is difficult to determine whether and to what degree poor psychosocial functioning is a cause of mental health difficulties, what is clear is that poor psychosocial functioning predates the onset of formal psychotic disorder (Addington and Addington,
1993). Widespread impairments in 'premorbid functioning' defined as functioning prior to the onset of illness - is typical of individuals who later develop psychosis (Hafner and an der Heiden, 1999; Agerbo et al., 2004; Addington et al. 2005; Jeppesen et al., 2008; Lucas et al., 2008; Tandberg et al., 2012). Addington et al. (2005) demonstrated that poor functioning which emerges in childhood and continues on a declining course was the best predictor of psychosocial outcome not only at illness onset, but 2 years after the initiation of treatment. This underlines that for many young people, functional deficits are already in place before psychosis formally manifests, and psychosocial disability apparent at the formal onset of psychosis is simply a continuation of earlier trajectories; these individuals are likely at risk of enduring illness and disability.

Intervention in this premorbid phase may be most effective to prevent long-term disability, but this is likely to prove challenging as these individuals may not come to the attention of clinical services until they present with clinical symptoms. This leads to questions as to whether an 'at risk' group can be identified and targeted by intervention prior to the manifestation of formal psychosis.

\section{Young people with NEET status: a candidate group for prevention of long-term psychosocial disability?}

The transition from school to employment is a critical time in a young person's life; failure to secure employment or access further training or education by the age of 25 places the individual at high-risk of long-term unemployment, deprivation and social exclusion (Rodwell et al., 2018); all of these are known risk factors predisposing individuals to the development of schizophrenia and other non-affective psychoses (Van Os et al., 2010; Kirkbride et al., 2012; Heinz et al., 2013). It is estimated that around $18 \%$ of the 20-24-year group are not in education, employment or training (i.e., NEET: OECD, 2015; Rodwell et al., 2018).

Factors such as lower socioeconomic status, motivation, parental unemployment and family fragmentation puts young people at risk of the NEET status (Eurofound, 2012; Powell, 2018), suggesting a vicious circle of social disadvantage and heightened risk of developing psychosis. A recent prospective 10-year study looking at predictors of NEET in young people showed that persistent mental health problems in adolescence, disruptive behaviours and frequent cannabis use were associated with a failure to make a successful transition from school to employment, further education or training (Rodwell et al., 2018). This raises the possibility that the link between mental health problems and psychosocial disadvantage is bi-directional, where emerging mental health problems are likely to contribute to poor educational attainment and psychosocial outcome, and vice-versa (Gladwell et al., 2015). Young people with the NEET status in general are therefore a candidate group for intervention and preventative strategies, and it is conceivable that successful interventions here might well reduce the numbers developing formal psychosis. Any such intervention would, of course, need to exist outside public health mechanisms to avoid potential medicalising of psychosocial disadvantage.

\section{Markers of psychosocial disability?}

The challenge of determining who to target with preventative interventions and the nature of such interventions is to identify pathological factors or markers that are relevant to specific clinical 
populations (Strauss and Carpenter, 1977). Early identification of potentially modifiable markers of poor psychosocial outcome holds out the prospect of stratification of targeted interventions to prevent long-term psychosocial disability.

A number of predictors and markers of psychosocial functioning have consistently been identified in psychosis, which include: poor adolescent premorbid adjustment, early appearance of negative symptoms, poor cognitive function, longer duration of untreated psychosis (DUP), early age of onset of psychosis and male gender (Malla and Payne, 2005; Lucas et al., 2008; Ayesa-Arriola et al., 2013; Rammou et al., 2017; Santesteban-Echarri et al., 2017). Further, there is evidence showing that markers such as impaired cognition and negative symptoms are apparent prior to the onset of illness, making them potential candidate targets to enhance functional improvement (Couture et al., 2006).

Cognitive impairments in psychosis can be considered as those falling within the broader domains of social cognition (SC), defined as the mental operations underlying social interaction (Adolphs, 2009), and neurocognition (NC), which describes a group of cognitive functions implicated in processes such as learning, memory and problem solving. SC and NC impairments tend to remain stable across the different stages of psychosis (Addington et al., 2006; Thompson et al., 2012; Lee et al., 2015), and deficits are also evident in first-degree relatives of individuals with schizophrenia (Janssen et al., 2003), likely suggesting that poor cognition is a possible trait marker of illness rather than a consequence of illness progression (Allott et al., 2011). Further, cognitive deficits are linked with a core of domains of psychosocial functioning in those with enduring psychosis (Green et al., 2000; Fett et al., 2011), FEP (Addington et al., 2006; Stouten et al., 2014; Santesteban-Echarri et al., 2017) and individuals with the UHR status (Chung et al., 2008; Thompson et al., 2012; Cotter et al., 2014; Lee et al., 2015). Similarly, persistent negative symptoms are evident in the early course of psychosis (both in UHR and FEP groups) and are associated with poor psychosocial outcome (Lin et al., 2011; Cornblatt et al., 2012; Piskulic et al., 2012; Addington et al., 2015). These findings indicate that negative symptoms and cognition may be a 'trait' indicator of long-term poor functioning in individuals with psychosis, perhaps reflecting neurodevelopmental differences (Lin et al., 2013b).

\section{Is there a neurodevelopmental pathway to psychosocial impairment?}

Impaired cognition, negative symptoms and poor psychosocial functioning develop long before the onset of frank disorder. These deficits seem to have their origins in adolescence, a critical stage for brain maturation, particularly in the social brain regions (Pantelis and Bartholomeusz, 2014). As we have shown, for some individuals, functioning at formal illness onset reflects an ongoing, often long-standing trajectory, persisting even when psychosis symptoms remit. It has been argued that these findings support a neurodevelopmental hypothesis of psychosis, and this subgroup is perhaps more neurologically impaired than those with good psychosocial functioning and intact cognition (Fenton and McGlashan, 1994; Kirkpatrick et al., 2001). Indeed, the regions of the brain which go through extended development during adolescence are the same as those underpinning SC and NC (Bartholomeusz and Allott, 2012; Lin et al., 2013). It is on this basis that it has been hypothesised that aberrations in the neurodevelopmental process, linked to cognitive deficits, lie at the heart of early and enduring psychosocial difficulty (McGlashan and Hoffman, 2000; Blakemore,
2008; Bartholomeusz et al., 2011). Interventions which are delivered during adolescence are therefore more likely to be more effective given the neuroplasticity of the brain at this stage (Bartholomeusz et al., 2011).

However, given that psychosocial impairments develop from an earlier age, one could also argue the reverse: cognitive impairments may be a secondary phenomenon arising from reduced or adverse social exposure and modelling during childhood and adolescence. This would require plausible early adverse psychosocial experiences affecting social and cognitive development. A link between early adverse childhood experience and anomalous psychosocial outcomes has been demonstrated by Stain et al. (2013), who found that childhood trauma was associated with poorer premorbid functioning and later psychosocial impairments in individuals with FEP. Such experiences have been shown in many studies to act as risk factors for psychosis: those who experience childhood trauma are 2.8 times more likely to develop psychosis in adulthood (Varese et al., 2012); trauma and neglect feature often in personal histories.

How might such experiences affect social development? Trauma can disrupt attachment mechanisms, in turn affecting interpersonal confidence and engagement which if untreated, are likely to be maintained over time (Stain et al., 2013). Early stressors such as childhood maltreatment can also lead to enduring brain dysfunction, and disrupt the development of cognition (Anda et al., 2006). For example, the hippocampus, which has a critical role in learning and memory function, is involved in inhibiting the stress response of the hypothalamic-pituitary-adrenal (HPA) axis through glucocorticoid pathways, but exposure to prolonged stress can disrupt this feedback loop resulting in hyper-reactive HPA response to subsequent normal life stressors (Barker et al., 2015). Dysregulation of this system, specifically the corticotropinreleasing hormone $(\mathrm{CRH})$ during stress, influences neuronal structure and hippocampal functions such as memory (Maras and Baram, 2012). Indeed, individuals exposed to childhood maltreatment are shown to have reduced hippocampal volume and lowered cognitive functioning in childhood and adulthood (Bremner, 2003; Anda et al., 2006; McCabe et al., 2012), further making these individuals more vulnerable to psychosocial impairments. Individuals who experience childhood trauma are therefore at high-risk of long-term psychosocial disability.

\section{Future directions}

Poor psychosocial functioning in young people should be an important intervention target regardless of its diagnostic association. Current symptom-focused early intervention approaches do not seem to affect psychosocial disability and therefore need re-thinking. An early intervention approach that addresses social disability is needed to ensure that disability does not become entrenched. Further, there is a window of opportunity to deliver broad spectrum interventions to young people who are NEET to reduce social disadvantage and marginalisation, and potentially reduce the numbers developing formal psychosis.

\section{Implications for universal interventions to prevent psychosocial disability}

As previously discussed, young people with the NEET status are a high-risk group where preventative interventions could be targeted to reduce socio-economic disadvantage and thus potentially reduce the numbers developing formal psychosis. However, since 
psychosocial disadvantage is not a clinical problem, any interventions within this group would have to occur outside health services. For example, the UK government has implemented a number of policies and initiatives to tackle unemployment in young people; these are largely focused on supported vocational interventions (Powell, 2018). Whilst there is strong empirical support for supported vocational interventions in individuals with mental health problems, these interventions are most effective when individuals are motivated, and this type of intervention may not be successful in complex NEET groups (Bond et al., 2014; Fowler et al., 2017). Interventions targeting motivation, interpersonal skills and general cognitive skills which are important for obtaining employment (such as planning and decision making), may help to tackle psychosocial impairment in these groups.

\section{Implications for indicated interventions for individuals with psychosis and psychosocial disability}

Secondly, there is a need for early indicated intervention in those with established poor premorbid functional trajectories in FEP and those at-risk of developing psychosis. An example of a novel intervention which specifically targets severe psychosocial disability in psychosis is Social Recovery Cognitive Behavioural Therapy (SRCBT; Fowler et al., 2009). A recent randomised controlled trial has demonstrated the effectiveness of SRCBT at increasing structured activity in FEP individuals with severe social disability, which had proved unresponsive to standard EIS (Fowler et al., 2017). Delivering SRCBT to young people who already have persistent psychosocial disability when they present to EIS, may help to prevent further decline in functioning and promote social recovery. Further, there is potential for the SRCBT to be refined to incorporate a cognitive remediation or social cognitive intervention in those with such deficits, to test whether this increases response to psychosocial intervention. Finally, interventions aimed at improving attachment and sequelae of trauma may also improve psychosocial functioning for young people.

\section{Conclusion}

Psychosocial impairments occur long before the onset of formal mental disorder, and 'untreated disability' seems to have a deleterious effect on outcome. Poor psychosocial functioning affects a number of young people, irrespective of whether they transition to psychosis. Delivering interventions at a universal level to 'at-risk' groups, such as young people who fail to make the transition from school to employment or training, may prevent longterm economic disadvantage and social marginalisation, potentially bolstering resilience against the development of severe mental health problems such as psychosis. Further, early indicated intervention for those with persistent poor psychosocial functioning in FEP and UHR groups that address motivation, interpersonal functioning and cognition, may be most effective at improving psychosocial functioning.

Acknowledgements. MB is partly funded by the NIHR CLAHRC-West Midlands. The views expressed here are not necessarily those of the NIHR or Department of Health.

Financial support. None.

Conflict of interest. None.

\section{References}

Addington J and Addington D (1993) Premorbid functioning, cognitive functioning, symptoms and outcome in schizophrenia. Journal of Psychiatry \& Neuroscience 18, 18-23.

Addington J, Saeedi H and Addington D (2005) The course of cognitive functioning in first episode psychosis: changes over time and impact on outcome. Schizophrenia Research 78, 35-43.

Addington J, Saeedi H and Addington D (2006) Influence of social perception and social knowledge on cognitive and social functioning in early psychosis. The British Journal of Psychiatry 189, 373-378.

Addington J, Liu L, Buchy L, Cadenhead K, Cannon T, Cornblatt B, Perkins D, Seidman L, Tsuang TM, Walker EF, Woods S, Bearden C, Mathalon D and McGlashan T (2015) North American prodrome Longitudinal Study (NAPLS 2): the prodromal symptoms. Journal of Nervous and Mental Disease 203, 328-335.

Adolphs R (2009) The social brain: neural basis of social knowledge. Annual Review Psychology 60, 693-716.

Agerbo E, Byrne M, Eaton WW and Mortensen PB (2004) Marital and labor market status in the long run in schizophrenia. Archives of General Psychiatry 61, 28-33.

Allott K, Liu P, Proffitt T-M and Killackey E (2011) Cognition at illness onset as a predictor of later functional outcome in early psychosis: a systematic review and methodological critique. Schizophrenia Research 125, 221-235.

Alvarez-Jimenez M, Priede A, Hetrick SE, Bendall S, Killackey E, Parker AG, McGorry PD and Gleeson GF (2012) Risk factors for relapse following treatment for first episode psychosis: a systematic review and meta-analysis of longitudinal studies. Schizophrenia Research 139, 116-128.

Anda RF, Felitti VJ, Bremner JD, Walker JD, Whitfield C, Perry BD, Dube SR and Giles WH (2006) The enduring effects of abuse and related adverse experiences in childhood: a convergence of evidence from neurobiology and epidemiology. European Archives of Psychiatry and Clinical Neuroscience 256, 174-186.

Ayesa-Arriola R, Manuel Rodríguez-Sánchez J, Pérez-Iglesias R, GonzálezBlanch C, Pardo-García G, Tabares-Seisdedos R, Vazquez-Barquero JL and Crespo-Facorro B (2013) The relevance of cognitive, clinical and premorbid variables in predicting functional outcome for individuals with first-episode psychosis: a 3 year longitudinal study. Psychiatry Research 209, 302-308.

Barker V, Gumley A, Schwannauer M and Lawrie SM (2015) An integrated biopsychosocial model of childhood maltreatment and psychosis. The British Journal of Psychiatry 206, 177-180.

Bartholomeusz C and Allott K (2012) Neurocognitive and social cognitive approaches for improving functional outcome in early psychosis: theoretical considerations and current state of evidence. Schizophrenia Research and Outcome 2012, 1-15.

Bartholomeusz CF, Killackey E, Thompson A and Wood SJ (2011) Interventions targeting social and vocational dysfunction in individuals with a schizophrenia spectrum disorder. In MS Ritsner (ed.), Handbook of Schizophrenia Spectrum Disorders. Vol. III. Dordrecht: Springer, pp. 173-207.

Birchwood M and MacMillan J (1993) Early intervention in schizophrenia. Australian and New Zealand Journal of Psychiatry 27, 374-378.

Birchwood M, Todd P and Jackson C (1998) Early intervention in psychosis: the critical-period hypothesis. British Journal of Psychiatry Supplement 172, 53-59.

Blakemore S (2008) Development of the social brain during adolescence. The Quarterly Journal of Experimental Psychopathology 61, 40-49.

Bond GR, Drake RE and Luciano A (2014) Employment and educational outcomes in early intervention programmes for early psychosis: a systematic review. Epidemiology and Psychiatric Sciences 24, 1-12.

Bremner JD (2003) Long-term effects of childhood abuse on brain and neurobiology. Child and Adolescent Psychiatric Clinics of North America 12, 271-29.

Chung YS, Kang D, Shin NY, Yoo SY and Kwon JS (2008) Deficits of Theory of Mind in individuals at ultra-high risk for Schizophrenia. Schizophrenia Research 99, 111-118. 
Cornblatt BA, Auther AM, Niendam T, Smith CW, Zinberg J, Bearden CE and Cannon TD (2007) Preliminary findings for two new measures of social and role functioning in the prodromal phase of schizophrenia. Schizophrenia Bulletin 33, 688-702.

Cornblatt BA, Carrion RE, Addington J, Seidmen L, Walker EF, Cannon TD, Cadenhead KS, McGlashan TH, Perkins DO, Tsuang MT, Wood SW, Heinssen R and Lencz T (2012) Risk factors for psychosis: impaired social and role functioning. Schizophrenia Bulletin 38, 1247-1257.

Correll CU, Galling B, Pawar A, Krivko A, Bonetto C, Ruggeri M, Craig TJ, Nordentofy M, Srihari VH, Guloksuz S, Hui CLM, Chen EYH, Valencia M, Juarez F, Robinson DG, Schooler NR, Brunette MF, Mueser KT, Rosenheck RA, Marcy P, Addington J, Estroff SE, Robinson J, Penn D, Severe JB and Kane JM (2018) Comparison of early intervention services vs treatment as usual for early-phase psychosis: a systematic review, meta-analysis, and meta-regression. JAMA Psychiatry $75,555-565$.

Cotter J, Drake RJ, Bucci S, Firth J, Edge D and Yung AR (2014) What drives poor functioning in the at-risk mental state? A systematic review. Schizophrenia Research 159, 267-277.

Couture SM, Penn DL and Roberts DL (2006) The functional significance of social cognition in schizophrenia: a review. Schizophrenia Bulletin 32, 44-63.

Eurofound (2012) NEETs - Young People not in Employment, Education or Training: Characteristics, Costs and Policy Responses in Europe. Luxembourg: Publications Office of the European Union.

Fenton SW and McGlashan T (1994) Antecedents, symptom progression, and long-term outcome of the deficit syndrome in schizophrenia. The American Journal of Psychiatry 151, 351-356.

Fett A-K, Viechtbauer W, Dominguez M, Penn DL, van Os $J$ and Krabbendam L (2011) The relationship between neurocognition and social cognition with functional outcomes in psychosis. Neuroscience and Behavioural Reviews 35, 573-588.

Fowler D, Hodgekins J, Painter M, Reilly T, Crane C, Macmillan I, Mugford M, Croudace T and Jones PB (2009) Cognitive behaviour therapy for improving social recovery in psychosis: a report from the ISREP MRC Trial Platform study (Improving Social Recovery in Early Psychosis). Psychological Medicine 39, 1627-1636.

Fowler D, Hodgekins J, French P, Marshall M, Freemantle N, McCrone P, Everard L, Lavis A, Jones PB, Amos T, Singh S, Sharma V and Birchwood M (2017) Social recovery therapy in combination with early intervention services for enhancement of social recovery in patients with first-episode psychosis (SUPEREDEN3): a single-blind, randomised controlled trial. The Lancet Psychiatry 5, 41-50.

Fusar-Poli P, Byrne M, Valmaggia L, Day F, Tabraham P, Johns L and McGuire P (2010) Social dysfunction predicts two years clinical outcome in people at ultra-high risk for psychosis. Journal of Psychiatric Research 44, 294-301.

Gladwell D, Popli G and Tsuchiya A (2015) Estimating the impact of health on NEET status. Sheffield Economics Research Paper Series. Available at https://www.sheffield.ac.uk/economics/research/serps/articles/2015_016 (Accessed 20 May 2018).

Green MF, Kern RS, Braff DL and Mintz J (2000) Neurocognitive deficits and functional outcome in schizophrenia: are we measuring the "right stuff"? Schizophrenia Bulletin 26, 119-136.

Hafner $\mathbf{H}$ and an der Heiden W (1999) The course of schizophrenia in the light of modern follow-up studies: the ABC and WHO studies. European Archives of Psychiatry and Clinical Neuroscience 249, 14-26.

Heinz A, Deserno L and Reininghau U (2013) Urbanicity, social adversity and psychosis. World Psychiatry 12, 187-197.

Heinze K, Lin A, Nelson B, Reniers RLEP, Upthegrove R, Clarke L, Roche A, Lowrie A and Wood SJ (2018). The impact of psychotic experiences in the early stages of mental health problems in young people. $B M C$ Psychiatry 18, 214.

Hodgekins J, Birchwood M, Christopher R, Marshall M, Coker S, Everard L, Lester H, Jones P, Amos T, Singh S, Sharma V, Freemantle $N$ and Fowler D (2015a) Investigating trajectories of social recovery in individuals with first episode psychosis: a latent class growth analysis. The British Journal of Psychiatry 207, 536-543.
Hodgekins J, French P, Birchwood M, Mugford M, Christopher R, Marshall M, Everard L, Lester H, Jones P, Amos T, Singh S, Sharma V, Morrison T and Fowler D (2015b) Comparing time use in individuals at different stages of psychosis and a non-clinical comparison group. Schizophrenia Research 161, 188-193.

Iorfino F, Hermens DF, Cross SPM, Zmicerevska N, Nichles A, Badcock CA, Groot J, Scott EM and Hickie IB (2018) Delineating the trajectories of social and occupational functioning of young people attending early intervention mental health services in Australia: a longitudinal study. British Medical Journal Open 8, 3.

Janssen I, Krabbendam L, Bak M, Hanssen M, Vollbergh W, de Graaf R and van Os J (2003) Childhood abuse as a risk factor for psychotic experiences. Acta Psychiatrica Scandanavica 109, 38-45.

Jeppesen P, Petersen L, Thorup A, Abel AB, Øhlenschlæger J, Christensen TØ, Karup G, Jorgensen P and Nordentoft M (2008) The association between pre-morbid adjustment, duration of untreated psychosis and outcome in first-episode psychosis. Psychological Medicine 38 1157-1166.

Kirkbride JB, Errazuriz A, Croudace TJ, Morgan C, Jackson D, Boydell J, Murray R and Jones PB (2012) Incidence of schizophrenia and other psychoses in England, 1950-2009: a systematic review and meta-analyses. Plos One 7, 3.

Kirkpatrick B, Buchanan RW, Ross DE and Carpenter Jr WT (2001) A separate disease within the syndrome of schizophrenia. Archive of General Psychiatry 58, 165-171.

Lee TY, Hong SB, Shin NY and Kwon JS (2015) Social cognitive functioning in prodromal psychosis: a meta-analysis. Schizophrenia Research 164, 28-34.

Lin A, Wood SJ, Nelson B, Brewer WJ, Spiliotacopoulos D, Bruxner A, Broussard C, Pantelis C and Yung AR (2011) Neurocognitive predictors of functional outcome two to 13 years after identification as ultra-high risk for psychosis. Schizophrenia Research 132, 1-7.

Lin CH, Huang CL, Chang YC, Chen PW, Lin CY, Tsai GE and Lane HY (2013a) Clinical symptoms, mainly negative symptoms, mediate the influence of neurocognition and social cognition on functional outcome of schizophrenia. Schizophrenia research 146, 231-237.

Lin A, Wood SJ and Yung AR (2013b) Measuring psychosocial outcome is good. Current Opinion in Psychiatry 26, 138-143.

Lucas S, Redobaldo-Hodge M, Shores A, Brennan J and Harris A (2008) Predictors of outcome three years after diagnosis of first episode psychosis. Psychiatry Research 161, 11-18.

Malla A and Payne J (2005) First-episode psychosis: psychopathology, quality of life, and functional outcome. Schizophrenia Bulletin 31, 650-671.

Mangalore R and Knapp M (2007) Cost of schizophrenia in England. The Journal of Mental Health Policy and Economics 10, 23-41.

Maras PM and Baram TZ (2012) Sculpting the hippocampus from within: stress, spines, and CRH. Trends Neuroscience 35, 315-324.

McCabe KL, Maloney EA, Stain HJ, Loughland CM and Carr VJ (2012) Relationship between childhood adversity and clinical and cognitive features in schizophrenia. Journal of Psychiatric Research 46, 600-607.

McGlashan T and Hoffman R (2000) Schizophrenia as a disorder of developmentally reduced synaptic connectivity. Archives of General Psychiatry 57, 637-648.

McGorry PD, Killackey E and Yung A (2008) Early intervention in psychosis: concepts, evidence and future directions. World Psychiatry 7, 148-156.

National Institute for Health and Clinical Excellence (2014) Schizophrenia: Core Interventions in the Treatment and Management of Schizophrenia. London: National Institute for Health and Clinical Excellence.

Pantelis C and Bartholomeusz CF (2014) Social neuroscience in psychiatry: pathways to discovering neurobiological risk and resilience. World Psychiatry 13, 146-147.

Piskulic D, Addington J, Cadenhead K, Cannon TA, Cornblatt B, Heinssen R, Perkins DO, Seidman LJ, Tsuang MT, Walker EF, Woods SW and McGlashan TH (2012) Negative symptoms in individuals at clinical high risk of psychosis. Psychiatry Research 196, 220-224.

Powell A (2018) NEET: Young People Not in Education, Employment or Training. House of Commons Library: Briefing Paper. 
Epidemiology and Psychiatric Sciences

145

Rammou A, Fisher HL, Johnson S, Major B, Rahaman N, ChamberlainKent $\mathbf{N}$ and Stone JM (2017) Negative symptoms in first-episode psychosis: clinical correlates and 1-year follow-up outcomes in London Early Intervention Services. Early Intervention in Psychiatry, 1-10.

Rodwell L, Romaniuk H, Nelsen WB, Carlin JB, Lee KJ and Patton GC (2018) Adolescent mental health and behavioural predictors of being NEET: a prospective study of young adults not in employment, education, or training. Psychological Medicine 48, 861-871.

Santesteban-Echarri $O$, Paino $M$, Rice S, González-Blanch C, McGorry PD, Gleason J and Alvarez-Jimenez M (2017) Predictors of functional recovery in first-episode psychosis: a systematic review and meta-analysis of longitudinal studies. Clinical Psychology Review 58, 59-75.

Stain HJ, Brønnick K, Hegelstad WTV, Joa I, Johannessen JO, Langeveld J, Mawn L and Larsen TK (2013) Impact of interpersonal trauma on the social functioning of adults with first-episode psychosis. Schizophrenia Bulletin 40, 1491-1498.

Stouten LH, Veling W, Lan W, van der Helm M and van der Fag M (2014) Psychotic symptoms, cognition and affect as predictors of psychosocial problems and functional change in first-episode psychosis. Schizophrenia Research 158, 113-119.

Strauss JS, Carpenter Jr WT (1977) Prediction of outcome in schizophrenia: III. Five-year outcome and its predictors. Archives of General Psychiatry 34, 159-163.
The Organisation for Economic Cooperation and Development (OECd) (2015). OECD Employment Outlook 2015. Paris: OECD Publishing.

Tandberg M, Ueland T, Andreassen OA, Sunder K and Male I (2012) Factors associated with occupational and academic status in patients with first-episode psychosis with a particular focus on neurocognition. Social Psychiatry and Psychiatric Epidemiology 47, 1763-1773.

Thompson A, Papas A, Bartholomeusz C, Allots K, Amminger GP, Nelson B, Wood S and Young A (2012) Social cognition in clinical "at risk" for psychosis and first episode psychosis populations. Schizophrenia Research 141, 204-209.

United Nations Convention on the Rights of Persons with Disabilities (2006). Available at http://www.un.org/disabilities/documents/convention/ convention_accessible_pdf.pdf (Accessed 20 June 2018).

van Os J, Kenis G and Rutten BPF (2010) The environment and schizophremia. Nature 468, 203-212.

Velthorst E, Nieman DH, Linszen D, Becker H, de Haan L, Dingemans PM, Birchwood M, Patterson P, Salokangas RK, Heinimaa M, Heinz A, Juckel G, Reventlow HGV, French P, Stevens H, Schultze-Lutter F, Klosterkotter J and Ruhrmann S (2010) Disability in people clinically at high risk of psychosis. British Journal of Psychiatry 197, 278-284.

Varese F, Stets F, Drukker M, Lieverse R, Lataster T, Viechtbauer W, Read J, van Os J and Bentall R (2012) Childhood adversities increase the risk of psychosis: a meta-analysis of patient, control, prospectiveand cross-sectional cohort studies. Schizophrenia Bulletin 38, 661-671.

https://doi.org/10.1017/S2045796018000495 Published online by Cambridge University Press 